\title{
A mathematical model for optimum single-commodity distribution in the network of chain stores: a case study of food industry
}

\author{
Mohsen Cheshmberah $^{\mathrm{a}^{*}}$, Mohammad Reza Zahedi ${ }^{\mathrm{a}}$, Ali Hadizadeh ${ }^{\mathrm{b}}$ and Seyed Mehdi Tofighi ${ }^{\mathrm{c}}$
}

${ }^{a}$ Department of Industrial Engineering, Iran University of Science \& Technology, Tehran, Iran

${ }^{b}$ Department of Engineering and Management, Linkoping University Sweden

${ }^{c}$ Department of Industrial Engineering \& System Improvement, IMD

\section{A R T I C L E I N F O AB S T R A T}

Article history:

Received March 25, 2011

Received in Revised form

May, 12, 2011

Accepted 14 May 2011

Available online

15 May 2011

Keywords:

Logistics

Distribution network

Move and store

Chain stores

Single-commodity

Mathematical model
Distribution refers to the steps taken to move and store a product from the suppliers to a customers in the supply chain and is a key driver of the overall profitability of a firm and overall supply chain. In this paper, a problem regarding managing of the move and store of goods are articulated and a mathematical model is presented to solve the model. The objective function is the total costs of distribution network, including transportation, storage rental, general warehousing, goods damages due to the transportation and storage, procurement, packing, and finally loading and unloading costs. The cost components described are defined based on the assumptions for a real distribution network of a chain stores firm. The aim of developing such a model is to find the optimum pattern to move and store goods based on the minimum cost of the distribution network.

\section{Introduction}

During the past few decades, we have faced an increasing trend on competition in global economy, which forces many firms to reduce their costs. How to source products from the most appropriate manufacturing facility, how to keep the balance between inventory, transportation and manufacturing costs, and how to match supply and demand are concerned by each company (Simchi-Levi, et al., 2008). Therefore, the distribution process in a logistics network cannot be managed by try and error. Distribution is normally called a set of steps taken to move and store a product from the suppliers to different customers in the supply chain and it is a key driver of the overall profitability of a firm and overall supply chain because it directly impacts both the supply chain cost and the customer satisfaction. Good distribution can be used to achieve a variety of supply chain objectives ranging from low cost to high responsiveness (Chopra, 2003).

Generally in some firms (like the chain stores), the costs associated with the distribution network encompass a large share of the firm's total costs. Therefore, the firms can attain remarkable cost saving by improving its distribution network. Consequently, the location allocation problems in the

* Corresponding author. Tel. +982177240000

E-mail addresses: mcheshmberah66@gmail.com (M. Cheshmberah) 
distribution network have gained more attentions over the last years. Goods in many distribution networks are temporarily stored at the intermediate warehouses and consequently will be sent to the retailer's channels. There must be a tradeoff between different cost components, for instance, as the number of storage locations increase, the transportation costs decrease (Chopra, 2003).

Changing the distribution network design affects different supply chain costs such as inventories, transportation, facilities and handling, information, etc. As the number of facilities increases, the inventory and resulting inventory costs increase (Chopra, 2003). Thus, inappropriate pattern to move and to store goods increases costs of all partners of supply chain such as manufacturers, distributers, intermediaries, wholesalers, and retailers. Therefore, there is an increase in the wastes of distribution network and price of finished goods, and ultimately will cause reduction in customer satisfaction (Bowersox, et al., 1996) (Fleischmann, et al., 1998). The distribution problem is directly associated with location, transportation and inventory problems (Ballou, 1999). Many models are discussed in location problems including single-facility location problem, location-allocation problems, and location set covering problems. Basically, three general approaches can be used for solving move and store problems, namely exact methods, simulation models and heuristic approaches. Among the most important methods of exact methods used to solve these problems, we can mention operation research and network analysis models (Love, et al., 1983). Goods distribution network in the concept of logistics management contains set of nodes and arcs. Nodes are logistic facilities such as origins of goods supply, procurements, storage, and demand areas, while arcs represent the communications among these nodes (Ballou, 1999).

Melkote et al. (2001) presented the combined location allocation and network design problem wherein facilities are constrained by the capacity level based on the amount of demand they can serve. They later presented several numbers of inequalities to strengthen the linear programming relaxation of the capacitated facility location/network design problem (CFLNDP).

(Nozick, et al., 2001) proposed a trade-off between costs and customer service coverage for locating distribution centers with inventory and transportation costs and the approach was applied for an automotive manufacturer. Sheu (2003) proposed the model to determine facility location by considering rate of return on investment and demand over supply status and Ridlehoover (2004) presented the facility location problems with the utilization of Monte Carlo simulation and risk analysis to determine the best location with a P-median model. Miranda et al. (2004) presented a mixed-integer model and a heuristic solution approach to incorporate inventory control decisions into facility location and implemented their model for a distribution network design problem. Avittathur et al. (2005) used a non-linear mixed integer programming problem model (NLMIP) to determine the location of distribution centers by considering the impact of the central sale tax (CST) structure in their model. They also transformed their model into an approximate mixed integer programming problem (AMIP) to be solved with less complexity. They take the tradeoff between the CST structure and logistics efficiency into account, which might be influenced by CST policies. Shu et al. (2005) studied the stochastic transportation-inventory network design problem involving one supplier and multiple retailers with uncertain demand and safety stock.

Yang et al. (2007) investigated the logistics distribution centers location problem under fuzzy environment from with setup and turnover costs. Huijun et al. (2008) proposed a bi-level programming model to seek the optimal location for logistics distribution centers by considering benefits of customers and logistics planning departments as the planners in distribution.

Genennini et al. (2009) presented a cost-based and mixed-integer programming model for the dynamic location-allocation problem with customer service level and safety stock. They considered various types of facilities (e.g. warehouses, distribution centers), the choice of their locations and the assignment of customer demand. The model also includes tactical decisions regarding inventory control, production rates, and service-level determination.

From other viewpoint, distribution network design is an important issue in the field of SCM. Two important sub-problems of distribution network design are inventory and location decisions where in some approaches, inventory and location decisions are considered separately (Firoozi, et al., 2011). 
They proposed a nonlinear mixed integer mathematical model and a hybrid heuristic algorithm, based on simulated annealing that simultaneously determines the inventory and location decisions.

In this paper, we introduce a problem associated with the move, store the goods in a distribution network of a chain stores firm, and present a mathematical model to find the optimal move and store pattern based on the minimum total cost of the distribution network. The model is solved with the "Lingo" software package based on real data for one of the items in the network and the results are discussed.

\section{Problem definition}

We have implemented the case study of the proposed model of this paper for a real-world company located in Iran, which is responsible for packaging and distribution of all sorts of food products such as canned, dairy and grain foods, agriculture and animal husbandry industry such as olive oil, nuts, beans, seeds, sugar and meat productions. The firm is whose seller and it has offices on over fifty different locations of the country and worldwide.

The distribution network of goods is given as follows:

1) In this network, only one commodity is distributed.

2) For the single product, there are some supply points with the limited and specified capacity.

3) There are also some demand points with specified demand seeking to receive the good.

4) Due to the spatial and time gap between supply and demand, some goods must be stored inevitably and sent to the demand points after some time.

5) In each destination, there is a warehouse with a limited capacity of $\lambda$, which may sometimes reach to zero or less due to the partial or total occupation of the warehouse by other goods. Moreover, if the direct transportation of goods to each of the demand points cannot be applied for any reason, the warehouse capacity of the aforementioned demand point will be assumed to be zero.

6) If necessary, rental warehouses can be used at any demand point.

In order to fulfill the demand of the consumption areas, products should flow from the supply points to the demand points. However, sometimes the storage capacity of a particular consumption point is not enough or the stock house is completely filled. In addition, as mentioned earlier it might not be possible to directly transport goods to particular consumption point for different reasons. Therefore, the relevant goods should be stored in the warehouses of other consumption points either with adequate capacity or in the rental warehouses for some time. In this case, the available capacities for storing goods should be exploited and/or stock houses with specific capacities in destination points ought to be rented based on the lowest total cost of the distribution network. In addition, the amount of goods sent from each of the supply points to each of the storage locations (existing or rented warehouses) and to the destination areas (demand points) have to be stipulated and the optimal capacity of rental warehouses and the amount of products sent to the demand points from these warehouses must be specified. Indeed, the final response to the problem will present the optimal move and store pattern in the above cited distribution network. The following are some of the most important questions associated with our model.

- How many of the available warehouses, which of them and how much of their capacity should be employed for the storage of goods?

- How many of the rental warehouses, with what capacity and in what places should be rented?

- How many shipping items must be selected for distribution from storage points for shipping and where are the destinations?

\section{The mathematical model}

Table 1 and Table 2 summarize the parameters and decision variables used for the proposed model of this paper, respectively. 


\section{Table 1}

Parameters of the mathematical model

\begin{tabular}{|c|c|c|}
\hline Symbol & Description & Unit \\
\hline$p$ & Index of supply origins & - \\
\hline$i$ & index of destinations & - \\
\hline$n$ & Index of rented storage capacity points & - \\
\hline $\mathrm{P}$ & Number of supply origins & - \\
\hline I & number of destinations & - \\
\hline $\mathrm{N}$ & number of rented storage capacity points & - \\
\hline$C_{p i}$ & the cost of transportation per unit of goods from origin ' $p$ ' to destination ' $i$ ' & $\$ /$ Ton \\
\hline$C_{i j}$ & Transportation costs per unit of goods from destination ' $i$ ' to destination ' $j$ ' & $\$ /$ Ton \\
\hline$a_{p i}$ & Load damage cost per unit of moving goods from origins ' $p$ ' to destination ' $i$ ' & $\$ /$ Ton \\
\hline$a_{i j}$ & Load damage cost per unit of moving goods from destination ' $\mathrm{i}$ ' to destination $\mathrm{j}$ & $\$ /$ Ton \\
\hline$f_{\text {in }}$ & The cost of renting of the warehouse with capacity point ' $n$ ' at destination ' $i$ ' & $\$$ \\
\hline$h_{\text {in }}$ & Holding cost at the warehouse with capacity point ' $n$ ' at destination 'i' & $\$$ \\
\hline$a_{i}$ & Load damage cost at destination ' $i$ ' & $\$ /$ Ton \\
\hline$\sigma_{p}$ & the production capacity at supply $\mathrm{p}$ & Ton \\
\hline$l_{i}$ & the warehouse capacity at destination ' $i$ ' & Ton \\
\hline$s_{\text {in }}$ & the rented warehouse capacity with the capacity point ' $n$ ' at destination 'i' & Ton \\
\hline$b_{i}$ & Amount of demand at destination 'i' & Ton \\
\hline$Q$ & The total available budget for renting warehouses in the distribution network & $\$$ \\
\hline$m_{p}$ & the cost of production (purchasing) per unit good at (from) supply origin 'p' & $\$ /$ Ton \\
\hline$g_{i}$ & the cost of packing per unit good at destination ' $\mathrm{i}$ ' & $\$ /$ Ton \\
\hline$d_{p}$ & the cost of loading per unit good at supply origin ' $p$ ' & $\$ /$ Ton \\
\hline$d_{j}$ & The cost of unloading per unit cost at destination ' $i$ ' & $\$ /$ Ton \\
\hline \multicolumn{3}{|c|}{$p=1,2,3 \ldots \mathrm{P} ; i=1,2,3, \ldots \mathrm{I} ; n=1,2,3, \ldots \mathrm{N}$} \\
\hline
\end{tabular}

Table 2

Decision variables of the mathematical model

\begin{tabular}{cllll}
\hline Variable & Description & Unit & Interval & Type \\
\hline$t_{p i}$ & $\begin{array}{l}\text { the number of transported products form origin ' } \mathrm{p} \text { ' to } \\
\text { destination ' } \mathrm{i} \text { ' }\end{array}$ & Ton & {$[0,+\infty)$} & $\begin{array}{l}\text { Continuous } \\
\text { non-negative }\end{array}$ \\
$x_{i j}$ & $\begin{array}{l}\text { the number of transported products from destination ' } \mathrm{i} \text { ' to } \\
\text { destination ' } \mathrm{j} \text { ' }\end{array}$ & Ton & {$[0,+\infty)$} & $\begin{array}{l}\text { Continuous } \\
\text { non-negative }\end{array}$ \\
$y_{i n}$ & $\begin{cases}1 & \text { If the capacity point } n \text { is selected for the rented warehouse at destination } i \\
0 & \text { otherwise }\end{cases}$ \\
$u_{i}$ & Slack variable & & \\
\hline
\end{tabular}

\subsection{The objective function cost components}

There are different cost items associated with the objective function this model explained in this subsection. The objective function of this model is the total cost of the distribution network which includes seven cost titles as Transportation costs, Warehouse renting cost, Holding cost, Load damage costs, Procurement costs, Packing costs, and Loading and unloading costs. In the following, short descriptions of the above mentioned costs are presented.

\subsubsection{Transportation cost}

This cost, as one of the major components of the total distribution cost, includes the cost of transporting goods from supply origins to demand points. It also includes the costs associated with transportation from supply origins to the warehouses and from warehouses to the demand points. Generally, the transportation costs of good is calculated based on the list of the existing costs for the 
whole country arranged by planning and administration organization per Ton-Km transportation. It is also possible to determine the list of transportation costs per ton of some goods for each season. $C_{p i}$ is introduced as the cost of transportation per ton of products from the supply origin $p$ to destination $j$. $C_{i j}$ is introduced as the cost of transportation per ton of goods from destination $i$ (as the place of products storage) to destination $j$. Thus, the total transportation cost of the distribution network is as follows,

$\sum_{p} \sum_{i} c_{p i} \cdot t_{p i}+\sum_{i} \sum_{j \neq i} c_{i j} \cdot x_{i j}$

\subsubsection{Warehouse renting cost}

As we mentioned earlier, we could rent some warehouses but the capacities of these warehouses are different and consequently the renting costs are different. Let $f_{\text {in }}$ be the renting cost of a warehouse with capacity ' $n$ ' in the destination ' $i$ '. Therefore, Eq. (2) determines whether this cost item is chosen or not.

$\sum_{i} \sum_{n} f_{i n} \cdot y_{i n}$

\subsubsection{Holding cost}

Each warehouse has a set of general costs such as water charges, electricity, (single and three phase) fuel, manpower, materials handling equipments, insurance, etc which are defined as holding costs. For every rented warehouse, we consider holding and renting costs where these two values are either mentioned separately or sometimes in the form of an overall value. Therefore we have,

$\sum_{i} \sum_{n} h_{i n} \cdot y_{i n}$

\subsubsection{Load damage cost}

In general, in some distribution networks, there is a phenomenon known as damage cost, which is usually caused by two important factors namely, transportation and storage of goods. In other words, the amount of loads is deduced typically due to the transportation and/or storage. Normally, the load damage could be either "intentional" (e.g. Robberies) or it could be "unintentional" which occurs for different products in different situations. For instance, goods such as rice may have some moisture at the supply origin. This moisture brings about a temporary increase in the actual weight of the load. As the time goes on and especially due to the "transportation" or "storage" of goods, this moisture will fade away and the total weight of the load will decrease. Other examples could damage the products and their packages such as grains and sugar, tin of vegetable oils, containers of mineral waters, etc. The load damage depends on some factors including type of goods, supply source, destination, transporting distance, storage place, and even seasons i.e. storage and transport period. As a result, the parameter $a_{p i}$ is the cost of damage to loads per unit of products (Ton) from supply 'p' to demand ' $\mathrm{i}$ ' (Rial/Ton) $a_{i j}$ is considered as the similar cost but from the demand point ' $\mathrm{i}$ ' to the demand point ' $\mathrm{j}$ ', and $a_{i}$ is the damage cost for each unit of products due to the storage at demand point ' $i$ '. Accordingly, the total load damage of the distribution network is:

$\sum_{p} \sum_{i}\left(a_{p i}+a_{i}\right) \cdot t_{p i}+\sum_{i} \sum_{j \neq i} a_{i j} \cdot x_{i j}$

\subsubsection{Procurement cost}

Generally, the cost of purchasing goods or production per unit, are not taken into account as part of the distribution network costs. However, these costs should be considered as one of the components of the objective function if they differ from one another at each supply origin. 


\subsubsection{Packing cost}

Sometimes it is required to pack goods in smaller size and suitable with customers appeal after purchasing products from the relevant supplier and receiving them in the usual form of packing (e.g. in the bulk form or in the large boxes) and the packing process should be carried out. Similarly, if the packing costs vary in different regions, these costs should be included in the objective function.

\subsubsection{Loading and unloading costs}

There are always some costs, which must be paid per ton of products for loading goods either in supply origins or in storage place for unloading them at warehouses and destinations (demand points). These cost are usually the same for all areas, but as mentioned earlier for procurement and packing cost, if these costs are different in some regions, they have to be mentioned in the objective function.

Consequently, the constraints associated with the mathematical model developed for solving the problem posed in this paper are stated next.

\subsection{Constraints}

The constraints of the mathematical model are as follow:

1. The total number of received products from each supply origin cannot excess the capacity of that origin given in Eq. (6).

2. The amount of products transported to each destination should not exceed the capacity of the warehouse at that destination or the capacity of main warehouse plus the capacity of the rented warehouse in that region. This constraint is given by Eq. (7).

3. There will be output arcs (shipping) from one destination to other destinations (i.e. if a destination is considered as storage point) only if either the "available stock house" of the mentioned destination has "extra capacity" or a "rented warehouse" has been used in relevant destination (naturally, the priority is the available warehouse capacity of each region with its demand). Eq. (8) shows this constraint.

4. The subtraction of the total outflow from the total inflow of products in each destination should be equal to the demand of that destination (i.e. the balance equation for input and output at each demand point and the obligation of meeting demands). This constraint has been showed by Eq. (9).

5. The organization may be limited in terms of "budget availability" for renting warehouses, so the total cost of "renting" and "holding" should not go beyond a certain amount as stated in Eq. (10).

6. Several capacity points could be considered for a rented stock house in one region, but at most, one of these capacity points can be activated. However, this restriction can be abandoned if the user has no obligation to simultaneously use more than one rented warehouse in a destination (e.g. there are two warehouses, one with the capacity of 5000 tons and the other one with the capacity of 1000 tons) and Eq. (11) holds for this restriction.

7. The decision variables $t_{p i}$ and $x_{i j}$ are non-negative continuous variables as given in Eq. (12).

8. The decision variables $u_{i}$ and $y_{i n}$ are zero-one integer variables given by Eq. (13).

Consequently, developed mathematical model for the problem is as follows:

$\min \sum_{p} \sum_{i}\left(c_{p i}+a_{p i}+m_{p}+g_{i}+d_{p}+d_{i}\right) \cdot t_{p i}+\sum_{i} \sum_{j \neq i}\left(c_{i j}+a_{i j}+d_{i}+d_{j}+a_{i}\right) \cdot x_{i j}+\sum_{i} \sum_{n}\left(f_{i n}+h_{i n}\right) \cdot y_{i n}$

subject to

$\sum_{i} t_{p i} \leq \sigma_{p}, \forall p$ 
$\sum_{p} t_{p i} \leq l_{i}+\sum_{n} s_{i n} \cdot y_{i n}, \forall i$

$\sum_{j \neq i} x_{i j} \leq\left(l_{i}-b_{i}\right) \cdot u_{i}+\sum_{n} s_{i n} \cdot y_{i n} \quad, \forall i$

$\sum_{p} t_{p i}+\sum_{j \neq i} x_{j i}-\sum_{j \neq i} x_{i j}=b_{i}, \forall i$

$\sum_{i} \sum_{n}\left(f_{i n}+h_{i n}\right) \cdot y_{i n} \leq Q$

$\sum_{n} y_{i n} \leq 1, \forall i$

$t_{p i}, x_{i j} \geq 0, \forall i, \forall j, \forall p$

$y_{i n}, u_{i} \in\{0,1\}, \forall i, \forall n$

\section{Computational results}

To solve this problem, the above-mentioned model has been programmed by LINGO and tested with the network data. In this problem, one item is expressed with one supply source and 23 demand points. Results are indicated in Table 3.

\section{Table 3}

Response resulting from model implementation for the warehouse location and capacity for one of the items in the network

\begin{tabular}{llll}
\hline Row & Depot location & Type of warehouse & Capacity (Ton) \\
\hline 1 & Hormozgan & Rental & 1000 \\
2 & Hormozgan & Available & Available enough capacity \\
3 & Khuzestan & Available & Available enough capacity \\
4 & Tehran & Available & Available enough capacity \\
\hline
\end{tabular}

\section{Table 4}

The response resulting from model implementation for allocating destinations to warehouses for one the items in the network

\begin{tabular}{lllc}
\hline Row & Depot location & Destination & The amount of shipping products \\
\hline 1 & Hormozgan & Esfehan & 94.39999 \\
2 & Hormozgan & Kerman & 31.60000 \\
3 & Hormozgan & Khorasan & 153.8000 \\
4 & Hormozgan & Lorestan & 43.20000 \\
5 & Hormozgan & Azarbaijan sharghi & 88.60001 \\
6 & Hormozgan & Azarbaijan gharbi & 35.20000 \\
7 & Hormozgan & Fars & 76.39999 \\
8 & Hormozgan & Boushehr & 25.80000 \\
9 & Hormozgan & Sistan & 58.20000 \\
10 & Hormozgan & Kordestan & 49.00000 \\
11 & Hormozgan & Markazi & 28.20000 \\
12 & Hormozgan & Ghom & 44.40000 \\
13 & Hormozgan & Khuzestan & 124.8000 \\
14 & Khuzestan & Khuzestan & 19.20000 \\
15 & Khuzestan & Tehran & 39.20000 \\
16 & Tehran & Tehran & 54.00000 \\
17 & Tehran & Tehran & 42.00000 \\
18 & Tehran & Tehran & 26.76000 \\
19 & Tehran & Tehran & 48.00000 \\
\hline
\end{tabular}


Having considered the obtained results, the three available warehouses with empty capacities (Hormozgan, Khuzestan, and Tehran) are employed as depots. In addition, a rental warehouse with the capacity of 1000 tons will be required in Bandar Abbas. The allocation of demand points to depots is shown in Table 4. Naturally, if direct transportation is possible, the relevant products will be sent directly from the origin to the destination.

\section{Conclusions}

In this paper, a problem related to the move and store of goods is expressed and a mathematical model is presented to solve this problem. Normally, by changing any of the assumptions, we will create a new problem solving which requires providing appropriate solutions. The model presented in this study determines the optimum move and store pattern by considering the lowest total cost of the distribution network.

Although the model in this research has been developed to solve the specific case of a distribution network problem of a certain company for a single product, the issue raised can be generalized to the case with multi products in the future research.

\section{References}

Avittathur, B., Shah, J., \& Gupta, O. (2005). Distribution Centre Location Modeling for Differential Sales Tax Structure. European Journal of Operational Research , 191-205.

Ballou, R. H. (1999). Business Logistics Management. Prentice-Hall Publishing.

Bowersox, D., \& Closs, D. (1996). Logistical Management: The Integrated Supply Chain Process. New York: McGraw Hill.

Chopra, S. (2003). Designing the distribution network in a supply chain. Transportation Research Part E, $123-140$.

Firoozi, Z., Tang, S. H., \& Ariffin, M. K. (2011). Developing a hybrid algorithm for distribution network design problem. International Conference on Industrial Engineering and Operations Management, (pp. 771-775). Kuala Lumpur, Malaysia.

Fleischmann, B., Vannunen, J., \& Speranza, A. (1998). Advanced in distribution logistics. Springer Publishing.

Gebennini, E., Gamberini, R., \& Manzini, R. (2009). An integrated production-distribution model for the dynamic location and allocation problem with safety stock optimization. Int. J.ProductionEconomics , 286-304.

Huijun, S., Ziyou, G., \& Jianjun, W. (2008). A bi-level programming model and solution algorithm for the location of logistics distribution centers. Applied Mathematical Modelling , 610-616.

Love, R. F., Morris, J. G., \& Wesolowsky, G. O. (1983). Facilities Location. ORSA Publishing.

Melkote, S., \& Daskin, M. S. (2001). Capacitated facility location/network design problems. European Journal of Operational Research , 481-495.

Miranda, P., \& Garrido, R. (2004). Incorporating inventory control decisions into a strategic distribution network design model with stochastic demand. Transportation Research Part E , 183-207.

Nozick, L., \& Turnquist, M. (2001). Inventory, Transportation, Service Quality and the Location of Distribution Centers. European Journal of Operational Research , 362-371.

Ridlehoover, J. (2004). Applying Monte Carlo Simulation and Risk Analysis to the Facility Location Problem. The Engineering Economist , 237-252.

Sheu, J. (2003). Locating Manufacturing and Distribution Centers: an Integrated Supply Chain-Based Spatial Interaction Approach. Transportation Research, Part E , 381-397.

Shu, J., Teo, C., \& Shen, Z. J. (2005). Stochastic Transportation-Inventory Network Design Problem. Operations Research , 48-60.

Simchi-Levi, D., Kaminsky, P., \& Simchi-Levi, E. (2008). Designing and Managing the Supply Chain. New York: McGraw-Hill/Irwin.

Yang, L., Ji, X., Gao, Z., \& Li, K. (2007). Logistics distribution centers location problem and algorithm under fuzzy environment. Journal of Computational and Applied Mathematics , $303-315$. 